\title{
Macalester College
}

\section{DigitalCommons@Macalester College}

Sociology Honors Projects

Sociology Department

Spring 5-1-2019

\section{"Being Able to Breathe Publicly:" Trans and Gender Nonconforming People Healing through Embodied Activity}

KP Blake-Leibowitz

MacalesterCollege, kpbleibowitz@gmail.com

Follow this and additional works at: https://digitalcommons.macalester.edu/soci_honors

Part of the Sociology Commons

\section{Recommended Citation}

Blake-Leibowitz, KP, "“Being Able to Breathe Publicly:" Trans and Gender Nonconforming People Healing through Embodied Activity" (2019). Sociology Honors Projects. 61.

https://digitalcommons.macalester.edu/soci_honors/61 


\title{
Running Head: HEALING THROUGH EMBODIED ACTIVITY
}

\author{
"Being Able to Breathe Publicly:" \\ Trans and Gender Nonconforming People Healing through Embodied Activity*
}

KP Blake-Leibowitz

Professor Erik Larson, Advisor

Department of Sociology

Macalester College

Word Count $=9,165$

May $1^{\text {st }}, 2019$

\footnotetext{
* This research expands from a genealogy of trans, queer, and feminist scholars to whom I am most indebted.

Without their time, research, intelligence and will to re-center marginalized experiences and theorize on embodiment, gender, and queerness I would not have had the ability to complete this research. I am forever thankful to the professors, particularly Erik Larson and Corie Hammers, as well as to my friends, family and loved ones who have provided endless support and guidance. But most of all, I want to thank the people who participated in this research; they have been most integral to this work, and I am appreciative of their willingness to be vulnerable, patient, and supportive.
} 


\section{ABSTRACT}

Sociological research on transgender and gender nonconforming (gnc) people has emphasized the interplay between identity and institutional contexts as constraining through hegemonic norms and dominant ideologies on sex and gender. Research in feminist trauma studies focused on insidious and embodied trauma has demonstrated numerous prospects for healing. In bridging these two fields of study through a socio-phenomenological lens, this paper shows how consciousness emerges in ways that facilitate the development of a type of bodily agency. Empirically, the paper examines whether trans and gnc people can use movement-based activities for healing, and how that healing occurs in particular spaces. In reflection of the impacts of insidious traumas on both the body and mind, this paper radically re-centers the body to consider the potential for healing through movement. Through an analysis of in-depth interviews with trans and gnc people on their engagement with movement-based activities, I argue that participation in movement, on one's own terms, enables a practice of bodily freedom. Moving beyond constraint and regulation, bodily agency requires a degree of bodily awareness (consciousness) that can emerge through participating in movement-based activities in transcentered and "personally-public" spaces. These results show that movement-based activities support trans and gnc people in healing from the impacts of insidious traumas. These findings have empirical importance, exemplifying the power of fostering intentionality through movement practices, as well as theoretical implications for understanding dynamics of agency and constraint in processes of healing from embodied oppression outside of formal therapeutic landscapes. 
Hegemonic ideologies of sex and gender are essentialized and constructed into binary categories. This "tyranny of gender" (Doan 2010:635) is embedded in the practices and spaces we engage in every day, perpetually constraining actions and bodily autonomy. Although the constraints of gender are implicated in everyone's lives, this disproportionately effects trans and gender nonconforming people (Mizock and Lewis 2008). Transphobia and related violencespanning prejudice, discrimination and overt interpersonal and structural violence-directly affects the body. Direct transphobic violence as well as more 'insidious' forms of discrimination can result in symptoms similar to those of PTSD (Root 1992). If the body is impacted by strict and constraining binary ideals of gender, how can the bodies of trans and gnc people be implicated in processes of healing?

Healing through the body has been theoretically and empirically considered in feminist trauma studies and psychology. Engaging in formal therapeutic practices like Dance/Movement Therapy (D/MT) has been shown to provide positive outcomes for trans and gnc people; reducing gender dysphoria, increasing embodied awareness, and addressing how gender is “experienced and expressed in the body" (Hanan 2012:2). However, considering the often inaccessible and often pathologizing aspects of formal therapeutic landscapes (Van Ingen 2004), research on engagement in informal therapeutic landscapes for trans and gnc people may provide insight on additional modalities of healing.

Research in physical activity and sport (PA/S), although limited, has been investigated outside of formal therapeutic landscapes (Van Ingen 2004; Leedy 2009; Karcher and Caldwell 2014; Chernova 2016; Elling-Machartzki 2017). Although feminist sport sociologists have typically focused on the exclusionary and marginalizing aspects of PA/S for non-normative bodies (Elling-Machartzki 2017), recent studies have considered the potential for physical 
activity to be empowering (Elling-Machartzki 2017; Chernova 2016). These studies also emerged as an attempt to ground post-structuralist and queer theoretical perspectives in the lived experiences of trans people (Elling-Machartzki 2017). My research extends from these studies, continuing a practice of grounding theories in the lived narratives of trans and gnc people, while broadening the scope of research in two ways.

Despite previous emphasis on trans and gnc people's engagement in organized sports (Elling-Machartzki 2017) and dance (Chernova 2016), this research encompasses a more expansive definition of movement. This is particularly important when considering healing through movement to be feasible, regardless of physical dis/ability, time and monetary constraints. Including additional forms of movement further allows for increased understanding in the role of intention and awareness (Heyes 2018) in movement-based activities. ${ }^{1}$ Second, this study expands previous research in considering the role of "socio-spatial constructions" (Bailey 2014) of movement spaces. This emphasis centers movement as a mechanism for trans and gnc people to navigate experiences of bodily agency and constraint as well as hyper-/invisibility, in both public and private spaces (Chernova 2016). In line with previous findings this research suggests that engaging in trans-centered spaces on one's own terms allows trans and gnc people to navigate the hyper-/invisibility paradigm. Moreover, this research exemplifies how engaging in individual practice in group-based movement activities (e.g. yoga class, running group) or “personally-public" movement spaces, as one participant referred, provide similar benefits, increasing agency and bodily autonomy.

\footnotetext{
1 I use the term 'movement' to denote physical activities which include: formal/organized team sports, running, yoga, dance, as well as walking, bodywork, breathwork, acting, and most other activities involving the body.
} 
Understanding the body as central to the lived experiences and subjectivity of gendered embodiment (Elling-Machartzki 2017), studying trans and gnc people's participation in movement-based activities becomes critical in expanding sociological conceptions of the interactions between gender, embodiment, and socio-spatial constructions within hegemonic gendered structures. Through an analysis of in-depth interviews with trans and gender nonconforming people, I argue that trans and gnc people's participation in movement-based activities can transcend the tyranny of gender and foster healing from embodied oppression. Moving beyond constraint and regulation, bodily agency requires awareness that can emerge by connecting with trans-centered and "personally-public" spaces. Enabling a practice of bodily freedom, movement creates the capacity to heal.

To understand how the body is involved in and effected by social phenomena and space, I examine questions of agency and the body, both theoretically and empirically. In the following section I review literature on the gendered body and participation in movement in three parts. First, I examine literature on the ways the trans body simultaneously has agency and is constrained, drawing from theories on structuration and phenomenology; second, I consider the traumatic impacts of hegemonic gender structures on the body and implications for healing through movement; and third, I assess the ways the body and movement are located in space. After a review of the methodology used, I present an analysis of the interviews conducted with trans and gnc people. The analysis will be divided into two sections; the impacts of movement on the individual body, and the communal and socio-spatial constructions and subsequent impacts on movement practice. Finally, I reflect on the contributions of this research, limitations, and the ways it can and should be expanded upon. 


\section{THEORETICAL CONSIDERATIONS}

In recent years, a culmination of studies on the body and embodiment have emerged in sociological literature as a means of expanding the "disembodied" discussions of social experiences (Adelman and Ruggia 2016:907). However, there exists a significant theoretical and empirical gap in sociological literature that negates the embodied experiences of trans and gnc people, particularly as it relates to topics beyond marginalization. The literature lacks in considering the socio-spatial implications and experiences of the embodiment of gender for trans and gnc people. To fill this gap, I draw from trans, queer and feminist scholarship that situates the embodied experiences of shaping and being shaped by the relations between the "material and institutional dimensions...of social relations" (Adelman and Ruggia 2016:909).

\section{Locating Agency: Theories on Structuration and Phenomenology}

This research is centered on the concept of the self and identity as embodied and impacted by social relations (Giddens 1991). In constructing identity and a sense of self, we learn to 'do' gender through the people, structures, and institutions around us (West and Zimmerman 1987$)^{2}$. Gendered embodiment has been identified as a crucial marker of identity and power relations, and such lived experiences are embedded in hegemonic structures and practices, including physical activity (Elling-Machartzki 2017). As Giddens claims, “...routine control of the body is integral to the very nature both of agency and of being accepted (trusted)

\footnotetext{
${ }^{2}$ It should be noted that race, class, ability, and other markers of identity also denote specific and unique embodied experiences based on people's multiple and intersecting identities. However, for the purpose of this research I intend to emphasize the ways gender is embodied and experienced, specifically regarding gender expressions and identities that are deemed "deviant."
} 
by others" (Giddens 1991:57). However, acceptance is predicated on the legibility of the body as it relates to "normality" and "normal" appearances (Giddens 1991:58). Normality is constructed by dominant ideologies that create a gendered regulatory regime (Doan 2010). Agency and control are foundational to maintaining an understanding of the self and identity (Giddens 1991), and therefore must be centered in conceptualizing how the trans and gnc body can (and does) transcend such constraint. While the body and experience are constrained by a gendered regulatory regime, constraint does not negate the presence or potential of the individual to have agency (Giddens 1984). To situate experiences of the agency/constraint dynamic within the lived, embodied experiences of trans and gnc people I draw on theories in phenomenology. Phenomenology is a field of philosophical thought that interrogates the study of phenomena as it is experienced, perceived, and expressed in our consciousness (Allen Collinson 2009). I specifically center a queer phenomenological orientation of perception and sensation regarding our own and others lived embodied experiences, through the lens of feminist writer, scholar and activist Sara Ahmed. This orientation emphasizes individual agency as well as the (dis)orienting experiences of embodying a queer time space (2006). For trans and gnc people, managing dynamics of queer embodied subjectivity and gendered body management is often a constant and complex experience (Elling-Machartzki 2017). Situating a phenomenological framework within a sociological context, I consider how gender is both embodied and experienced in relation to the structures that prescribe gendered ways of being on the body. Therefore, a queer phenomenological lens situates gender as not only a "discursively constructed, binary power relation, but also [a] meaningful, dynamically embodied materialit[y] and identit[y] that [is] both structured and structuring” (2017:258). 
Through a "socio-phenomenological" approach (Elling-Machartzki 2017), I center the lived experiences of marginalized gendered embodiments in the context of structural constraints, specifically spaces, to highlight the relationship between agency and constraint. Drawing from theories on structuration and phenomenology provides a platform to identify mechanisms of healing through this complex tension. This approach expands beyond the focus in feminist sport sociological research on participation in physical activity as solely exclusionary and constraining for trans bodies (Elling-Machartzki 2017). Therefore, I consider movement-based activities for trans and gnc people through Michel Foucault's concept, as a "technology of the self." Such "technologies" are theorized as techniques which allow individuals particular agency over their own body, mind, and soul. These actions concern issues of self-making and processes of gaining subjectivity (Porter et al. 1989). I consider movement-based activities for trans and gnc people as a particular technology of the self which can be used "to acquire body awareness" and foster “(gender) identity development” (2017:258). Engaging in a practice that affirms control and autonomy over one's body, can function as a mechanism to manage experiences of embodied oppression and constraint (2017; Chernova 2016).

Empirically, previous research on trans people's embodied experiences and participation in PA/S has emphasized the importance of the trans body and self as both active and aware, as well as constrained and impacted by dominant norms (Elling-Machartzki 2017). Engaging in PA/S for trans people pursuing medical transitions has helped people navigate experiences of bodily change and transformation and was most beneficial when the social environment was 
supportive of a person's transition. ${ }^{3}$ However, physical structures like changing rooms and binary classifications in sporting competitions often reduced comfort. Participants felt most constrained during the "liminal transitioning process" (2017:265). While participation in PA/S can foster a powerful relationship with one's body, transgressing gendered norms, experiences where the body is read as "illegible" (Salamon 2010:76f.) i.e. non-normative in the gendered regulatory regime, can result in traumatic experiences (Mizock and Lewis 2008).

\section{Trauma and Healing Through the Body}

In addition to disproportionate amounts of physical violence, trans and gnc people experience discrimination and other forms of oppression that inflict harm on their physical, mental and emotional, and spiritual well-being. Root (1992) refers to these effects as "insidious traumas," cumulative experiences that threaten a person in ways that harm their body and mind. Insidious traumas differentially impact people based on their multiple and intersecting identities and experiences (1992). These traumas can occur for example, internally_as demonstrated in interpersonal dynamics which engage perpetrator's (un)conscious motivations and transpeople's internalized conflicts — or externally_as barriers encountered in the social world (Shelley 2008). Regardless of where these traumas emerge however, they elicit extensive violence to the

\footnotetext{
${ }^{3}$ A supportive environment was denoted by the use of affirming pronouns and language, as well as the support of a team to continue participation.
} 
bodymind $^{4}$ (Root 1992). I use this framing of trauma to consider the embodied impacts, beyond experiences which are typically framed to be solely psychological.

Violence to the trans and gnc body, from both institutional and social realms, becomes inscripted on the body as a particular habitus. Considering the ways bodies are built subjects, these experiences have been theorized to simultaneously "represent and produce pleasure and pain," as well as "alienation and resistance" (Adelman and Ruggi:913). To clarify, I do not intend to center the body as a way to reify hegemonic systems that define people with marginalized identities by an objectified 'body'. Rather I consider the body as an extension of the mind, through the lens of feminist theorist Elizabeth Grosz (1994). This conception identifies the mind and body as separate entities, relational outside of a normative mind over body hierarchal power dynamic. This reframing, questions the very basis of popular Western thought and philosophies by countering the Cartesian Dualism; which situates the mind as over and in control of the machine-like body (1994). From this perspective, I intend to disrupt notions of healing as solely occurring in the mind, a pathologizing legacy for trans and gnc people. Reconceptualizing the mind and body as deeply intertwined entities and extensions of one another (1994), both impacted by violence (Root 1992), broadens the potential for identifying mechanisms of healing.

Both formal and informal ${ }^{5}$ movement-based activities have been documented as beneficial for the bodymind, and represent a critical example of healing through the body. A

\footnotetext{
4 I use the term "bodymind" to denote Grosz' understanding of the interconnections between the body and mind, drawn specifically from Spinoza's Monism, which refute Western thought and Cartesian Dualism (1994).

${ }^{5}$ I consider 'formal' movement practices to be under the guise of formal therapeutic practices, which occur most often in clinical settings. I use the term 'informal' movement practices to reference non-clinical-based practices.
} 
popular practice used by clinical practitioners is Dance/Movement Therapy (D/MT): a

psychotherapeutic technique which integrates movement, embodied awareness, and emotional expression/modulation through a bodymind approach (Hanan 2012). The use of D/MT as a therapeutic practice for trans people has been influential in centering the somatic experiences of gender to provide a space to work through the impacts of insidious traumas. D/MT can be particularly significant for supporting trans people in formulating a sense of self (Hanan 2012). Throughout gender affirming transitions, the use of D/MT may support the client in addressing "how identity is experienced and expressed in the body" (Hanan 2012:2). This research provides evidence in the use of movement therapy as a means of healing through the body for trans and gnc people.

In addition to formal therapeutic practices, uses of running and dancing have been documented outside of therapeutic landscapes as mechanisms by which non-normative bodies can take up and move in space, individually (Chernova 2016; Karcher and Caldwell 2014; Leedy 2009) and collectively (Van Ingen 2004). Both running and dance have been shown to provide positive outcomes for people who struggle with depression, anxiety, body dysmorphia, stress and/or the effects of trauma and abuse (Leedy 2009; Van Ingen 2004). Running in particular for women $^{6}$ can provide increased body awareness, promote a sense of control of one's life, and increase feelings of empowerment (Leedy 2009). Studies on dance have additionally shown the ways dominant cultural perceptions of the body itself, in reflection of what defines a 'deviant' body, help dancers to further understand the body as a site of oppression (Karcher and Caldwell 2014). These movement practices foster recuperation, resistance and disruption to the

\footnotetext{
${ }^{6}$ Although trans women are women I assume these authors, in describing the experiences of running as beneficial to "women" to be referring to cisgender women due to current linguistic norms in academic research.
} 
disembodying experiences of oppression, and provide empirical evidence to the benefits of decentering formal, clinical and psychoanalytic, concepts of healing.

In centering movement-based activities, such as running and dance, rather than organized sports (professional or recreational), this research extends previous studies on trans people's experiences in sports (Elling-Machartzki 2017) and considers the role of conscious intentionality in movement practice. Bodily awareness can be both psychologically and spiritually therapeutic or it can be uncomfortable, invoking a negative self-consciousness. However, through intentional somatic awareness practice and bodily response, movement practice can be beneficial to the bodymind. Somatic practices have been theorized to have the potential to transform the negative experiences of self-consciousness (Heyes 2018). Situating theories on self-consciousness (Heyes 2018) in reflection of the experiences of trans and gnc people, provides empirical evidence to the impacts of increased bodily awareness through somatic practice.

Previous research emphasizes the role of social support (Van Ingen 2004; Chernova 2016) as beneficial to mitigating experiences of marginalization and insidious trauma (Mizock and Lewis 2008; Root 1992); however, minimal research has been done regarding the sociospatial composition of movement spaces. Considering the importance of space, time, and objects (including other beings) in phenomenological theories, it is vital to address the constructions of spaces regarding movement-based activities. To further address these gaps, I draw from theories in queer geography studies regarding the construction of spaces and in-/exclusion of queer bodies in space. 


\section{Socio-Spatial Constructions and the Trans/Gnc Body}

Bodies exist simultaneously as the space in which people experience life, as ideal representations of cultural norms, and as sites in and through which particular models of interaction are performed (Butler 1989; Gieseking 2013). Gender is both fluid and performative (Butler 1990; Doan 2010) as well as social and cultural (Gieseking 2013; Kinkaid 2018). Therefore, gender "transcends the boundary of the human body" (Doan 2010:638). Through a socio-phenomenological perspective, the gendered body must be understood as material and imagined in time and space (Gieseking 2013).

Bodies, and the environments they inhabit are enveloped in a "complex feedback relation...in which they mutually produce each other" (Doan 2010:638). The "cultural shaping" (Gieseking 2013) of the body is not only implicated in affecting the individual, but is being simultaneously recreated and responded to, which in-turn functions to shape and change the social spaces (Salamon 2010) we engage in. Therefore, identity is not only contingent on time and space, but is also constructed in relation to other bodies and other bodies responses to perceived gender. As previously mentioned, people are impacted by interactions in spaces depending on whether a body is read as "culturally legible or illegible" (Salamon 2010:76f.), often a determinant of one's safety. These experiences shape our internal "felt sense" (Salamon 2010) of gendered embodiment and the lived experiences within a space. The felt sense of legibility, the embodiment of a queer time and space, procures a desire to visualize and reach for a future where space is not in reference to hegemonic social power relations (Kinkaid 2018).

Spaces are often unavailable to the queer subject (Chernova 2016; Gieseking 2013; Doan 2010). Both public and private spaces, as well as the continuum in between and beyond, can be off limits particularly for trans and gnc bodies (Doan 2010; Gieseking 2013). Gender, is apparent 
not only within the physically constructed place, but also through the ways people perform and read gender in those spaces (Massey 1994). The limitations in access to spaces which violently exclude, additionally constrain identity exploration (Massey 1994); a deviation from the gendered norms cause numerous cultural contexts of subordination (Doan 2010).

The particular spaces that exclude queer bodies, and in this case specifically trans and gnc bodies, are often exclusionary as a result of the hyper-/invisibility paradigm (Chernova 2016). Public spaces require trans and gnc bodies to become visible through a number of processes; the hegemonic gaze which attempts to determine an essentialized "truth" about one's gender; instances with the medical, legal and political institutions where 'outing' oneself is often required. Private spaces on the other hand tend to render trans and gnc people invisible, for example, through internalized transphobia and hierarchies of 'true womanhood,' as well as being spoken for and by non-trans activists and scholars (Chernova 2016).

In reflection of these overt and insidious forms of exclusion, Dasha Chernova, in her research on collective dance practices for trans and gnc people, argues that collective movement spaces can foster increased visibility (on one's own terms) and agency (2016). As she claims: "The right to dance is both the entry into the spaces that are created for and by queers and the ability to transform one's body by dancing the wounds, and when dancing and attaining the visibility on its own terms, transforming the world around" (Chernova 2016:433). Similarly, in ballroom culture, dance and performance have been shown to also foster a reclamation of spatial marginalization and geographies of exclusion (Bailey 2014). Space, as defined by Bailey, "is a result of human action, interaction, and participation in a social space" (2014:494). Even beyond the realms of dance and performance spaces, participation in queer-centered running spaces can remove/escape the clinical gaze; specifically transcending normative ideas of health and 
wellbeing (Van Ingen 2004). Creating a "therapeutic landscape" (254), particularly through the practice of movement-based activities, has increased the potential for healing from embodied oppressions through movement. This research provides further empirical evidence to philosophical theorizations on movement-awareness practices (e.g. yoga, meditation, breathwork) as mechanisms for accessing particular bodily freedoms (Heyes 2018), thereby resituating bodily agency.

Previous research has emphasized the power of communal movement practice for queer bodies to reclaim spaces and embodied subjectivities on their own terms (Chernova 2016; Bailey 2014; Van Ingen 2004). This research directly extends from previous studies to address physical activities and spaces outside of communal dance practice as well as trans identities outside of the gender binary. In addition to providing empirical evidence to the power of movement-based activities as a radical reclamation of the trans and gnc body, I theoretically explore movement as an avenue of transformative power. Through trans and gnc people's participation in movementbased activities, I expand on current understandings of how the body can function as a site of healing in movement spaces.

\section{DATA AND METHODS}

To explore the ways trans and gender nonconforming people use and engage with movement-based activities, I used in-depth interviewing to give voice to and understand how people navigate constraint and have agency through physical activity. In-depth interviewing centers and privileges the perspectives of the people telling their "body self-narratives" (EllingMacharzki 2017:257). In line with a theoretical socio-phenomenological (Elling-Macharzki 2017) approach, I employ a phenomenological methodology (Rubin 1998; Salamon 2014) and an 
Interpretive Phenomenological Analysis (Allen-Collinson 2009). Both of these methodologies aim at privileging the narrative perspectives of research subjects as "uniquely suited... to describing their own subjectivity" (Salamon 2014:154) while also centering participants "sensemaking" (Allen-Collinson 2009;18) of such experiences and positionality. This methodology validates personal reflections on one's lived experiences, while situating them in a social and structural context, thereby highlighting the complex experiences of the tension between bodily agency and constraint.

I completed nine interviews with trans and/or gnc people who are 18 years or older, living in a large midwestern city. Participants were recruited on the basis of having interest in discussing movement-based activities in which they participate, and identifying with one or more of the following listed identities: transgender, trans, trans woman, trans man, trans masculine, trans feminine, femme, masculine of center, agender, genderfluid, gnc, genderqueer, and/or nonbinary. I contacted participants via phone, email, as well as through in-person conversations and utilized snowball sampling techniques to recruit participants, considering the potential concerns of trans and gnc people outing themselves, regarding safety, comfort, and the ethics of research.

Interviews lasted for up to one hour and were audio recorded for transcription purposes. The questions asked for information related to the types of movement-based activities people participated in, frequency of participation, reasons for participating, individual or communitybased participation, location of participation, how they felt when participating, and how they are aware of their gender throughout engagement in the activity. The activities discussed emerged from the participants and ranged from formal gendered team sports, such as volleyball or diving, to individual practices, such as running, walking, rock climbing weight lifting, and dance. 
Movement practices, such as participation in a yoga class, acting and theater, and drawing were also mentioned. While numerous themes emerged ${ }^{7}$ and should be considered in additional research, I center the ideas most frequently discussed for analysis.

I use the prefix of 'trans' and the term 'gender nonconforming' throughout this paper to denote trans identities within the binary, as well as between and beyond. ${ }^{8}$ Although I did not ask any identifying information or demographics beyond identification as trans and/or gender nonconforming and being over 18 years old, a range of gender identities and expressions, as well as race, class, ability, and sexuality were discussed and therefore assumedly represented in this small sample. Unless pronouns were specified by the participant, I utilize singular 'they' pronouns throughout, not to erase a participant's pronouns but to further maintain confidentiality. ${ }^{9}$

Overall, interviews provide in-depth contextual evidence of particular phenomena, specifically regarding reasons for engagement and experiences of participation in movementbased activities. Considering my particular positionality as a trans, genderqueer person, presenting my trans identity in the recruitment process, and having either immediate or once removed connection to most participants, I presume I had particular access to information that a

\footnotetext{
${ }^{7}$ I proceeded to formulate a coding scheme through the emerging themes in interviews, and subsequently through closer analysis of the transcribed interviews

${ }^{8}$ I acknowledge the power and importance of labels; however, for ease in explaining my research I consider the following identities and labels to be encompassed in the terms trans and gnc: transgender, trans, trans woman, trans man, femme, masculine of center, agender, genderfluid, gnc, genderqueer, and/or nonbinary.

${ }^{9}$ For the purposes of protecting participants' privacy with respect to their identities and experiences, I avoid the use of names and even pseudonyms to identify participants in my research.
} 
cisgender researcher may not have had; particularly through trust, based on close social connections, as well as the possible shared experiences of oppression based on gender identity and expression.

\section{ANALYSIS}

The following section reviews findings on the uses of movement-based activities as mechanisms for healing outside of formal therapeutic landscapes. This research is separated into two main findings; first, that movement functions as a mechanism that trans and gnc people use to access a felt sense and foster bodily awareness, and second, that socio-spatial landscapes determine whether a space is accessible or not to participate in a movement-based activity. Participation in movement-based activities in trans-centered spaces as well as spaces that do not render trans and gnc people hyper-/invisible can enable experiences of embodied freedom.

\section{Felt Sense and Bodily Awareness}

Participation in movement-based activities can function as an awareness practice (Heyes 2018) that fosters engagement with a 'felt sense' (Gayle Salamon 2010) of the body and can be empowering (Hanan 2012). Movement has the potential to refute the "normalizing judgement" from the dominant gaze to "cultivate a form of embodied freedom" (Heyes 2018:2). In line with this research, participants described movement as a way to access words and ideas. For example, one person stated: "I feel much more comfortable in general if I'm able to move freely, like it helps me process my words, process ideas." This sentiment was reflected throughout our interview, as she continued to move, jump, sway, and dance. In this way, nonverbal movement has the potential to liberate the trans/gnc body, outside of a heteronormative cisgender discourse 
and structure. This experience exemplifies a type of knowledge in and of the body which goes beyond discursive constraint.

Similarly, the inability to express feelings through words was brought up numerous times during my interviews; which, as Hanan claims, is a common sentiment experienced by many people who participate in somatic therapies (2012). In reflection of finding a movement practice, one person claimed, "There is some shit happening in my body and I don't want to sit and talk with [someone] about it, but I can be present with it." This represents a person's capacity to acknowledge visceral sensations and have an interest in working through negative embodied experiences, but not to have the ability or the desire to describe verbally what is going on or being experienced.

Another participant, in describing how she came to a movement practice and to dance, described feeling regular pain in parts of her body, similar to cramping. However, the first time she allowed her body to move in an authentic "honest" way, the pain ceded. She claims:

Eventually I kind of realized, and especially moving back here, like you know what, what if I just surrender and give up and see what happens? And in a minute, I was just like in the kitchen... and I remember...I was like ok, I'm just going to stop, stop trying to fix this, stop trying to do anything and just stopped. Stopped thinking, stopped doing anything and the body just moves... at that point it was more like a slow ok, so this [part of my body] hurts, and without thinking I'm stretching this way, and then if I need to sit down I'll sit down in this manner. So, there's really been a body evolution, or not evolution, but awakening, and it's been really an important healing process when I listen to it.

Throughout the retelling of this memory, she appeared to reappropriate the embodied memories she was describing, almost mirroring the movements yet in an intentional and controlled manner. For her, releasing pain through movement explicitly related to living a felt sense of 'truth' in her body, specifically in relation to gender. 


\section{Truth-telling}

The ability to better express or process feelings through movement was often tied to claiming or expressing truth. Particular actions or feelings in the body represented a felt sense of truth. For example, in having access to more dance and improvisation classes, one participant reflects on becoming more comfortable with authentic movement as a tool for experiencing truth. She describes: "If I'm saying something that's like 'oh fuck, this is who I am and this is what's up,' my hands just go up and I clap over my head." This movement operates as a tool for her, affirming a felt embodied truth. The assertion of truth in this instance operates particularly in making claims about her identity as a trans woman.

For another participant, felt truth is ascribed to sensations of breath and breathing. Particular movement practices, like yoga and running, have helped foster awareness of the breath and consequently awareness of truth telling. They differentiate moments where they are not telling the truth, in reflection of when they are not breathing. This awareness has further allowed them to connect with their body. In telling truths they claim, “...holding a relationship with my breath has made me be able to hold a relationship within very nuanced places in my body." The lived experiences of expression of feelings and truth through movement, or illuminated by movement, are integrated into a broader idea of reclaiming a disembodied sense of self.

A felt sense of truth was repeatedly described as living a type of "bodily freedom." This was most often experienced and exercised through participation in movement-based activities. Such experiences provide empirical evidence to Heyes' discussion of intentional movement practice as a mechanism for transcending negative self-consciousness and reasserting control and autonomy over one's body. Whether through dance, running, or weightlifting, movement provided a bodily awareness practice that helped participants engage with their bodies. 


\section{Breath and breathing}

Breathing and breathwork were brought up repeatedly throughout interviews as vital to and as a form of movement, a way to return to and be with your body, and as a noticing practice about the amount of space one is taking up. Breathing and breathwork was described as not only necessary for movement but also as a key somatic practice to being in relationship with the "nuanced parts" of one's body. People mentioned noticing the ways they constrain their bodies, or even regularly seeing other trans and gnc people constraining their bodies.

Movement-based activities for most people were only possible by way of breathing practices. As one person claimed about yoga: “[This] practice gave me access to the breathwork but also just being able to breathe publicly feels like such a big, um, like such a large act of resistance. Like cool, actually you just get to breathe." In many interviews large releases of breath occurred in reflection of people claiming truth about identity and experience, as if they were simultaneously challenging to say, while also being a relief to claim.

Breath and the capacity to breathe appear to be directly tied to the experience of taking up space and living one's truth. Breath and movement as an awareness practice allow for an increased sense of control over one's body. Acknowledging a specific felt sense reduced feelings of dysphoria and disconnect with their body that was the result of not feeling safe or comfortable to express their gender.

\section{Exploring Gendered Movements}

In an attempt to reduce dysphoria, previous research has shown that many trans people within the binary who pursue medical transitions engage in movement-based activities that affirm a felt sense of masculinity or femininity. Regarding a person's identification with masculinity, it was found that "competitive (team) sports and fitness [form] relatively safe spaces 
where they could express their 'hidden' body-selves” (Elling-Machartzki 2017:262).

Additionally, many of the people in this study on more formal sports teams were supported after disclosing their trans identity and were encouraged to continue participation throughout transition. For others, participation in formal sports created more dysphoria. Trans people participating in informal (recreational/non-competitive) sports however, documented feeling consistent support and were more likely to continue participating through transition (EllingMachartzki 2017). My research complicates these findings primarily due to my lack of emphasis on the experiences of engagement with movement-based activities over time and through medical transitions.

For many participants, movement was the activity that allowed them to explore and engage with their body. In discussing the experiences of acting as different gendered characters, one participant claimed:

Sometimes yeah, sometimes it feels like possibilities open up because like I'm so much more in tune, with like constantly making choices, and then...it can sometimes feel, um, limiting in some ways...And like exciting though too. Because then, if I felt like I was gonna use that movement in my everyday life, like I feel like that points toward the future, like what other characters can I choose to put in my body and then choose to have an effect on my daily life in the way that I move?

The exploratory aspects of movement, also described in dance, moshing, and diving, reflected the potential to engage with one's body in a positive way. In many instances exploratory movements were also discussed as "terrifying," however, those experiences were ultimately reflected on as additional knowledge and increased bodily awareness. These experiences similarly show that participation in physical activities is not only disciplining and constraining for trans people but is also empowering and supportive, thereby "(re)creating a body awareness" (Elling-Machartzki 2017:265). However, this is not just for trans people pursuing medical 
transitions. Engaging in movement for trans and gnc people without an emphasis on medical transitions expands on the potential of exploring gender affirming movements.

Overall, movement-based activities were described as small "acts of freedom" that have allowed the people whom I interviewed to engage in an intentional practice of being with their bodies. Simultaneously, movement has been shown to operate as a both a "transformative and terrifying" justification of existence for trans people, particularly in regard to taking up space. The feelings of movement as relinquishing constrained embodiments provide important implications for the potential to heal through movement. As Heyes identifies, movement and awareness practices, when intentional, can foster a type of bodily freedom (2018). However, I have found that this freedom is contingent on particular social conditions. The following section reviews the constructions of spaces that enable embodied experiences of freedom.

\section{Socio-Spatial Constructions and Access to Therapeutic Landscapes}

While movement has the potential to transform trans and gnc people's relationships with their body, it is important to emphasize the ways movement occurs in space. Engaging in collective dance and performance has been influential for trans and queer people to create and reclaim spaces that foster increased visibility on one's own terms. While movement-based activities can be transformative, specific conditions may render movement-based activities in/accessible to trans and gnc people. In line with previous research specific physical constructions of spaces, such as binary gendered bathrooms and changing rooms, were claimed to be uncomfortable and not inclusive. However, more often than not, participants emphasized the particular social constructions of spaces regarding the accessibility of movement-based activities. 
In line with Van Ingen's theories on the power of combining movement with communal practice for people with shared marginalized identities (2004:253), as well as Chernova (2016) and Bailey's (2014) discussions of collective remaking of movement spaces, several of the participants I interviewed offered further implications for the formation of "therapeutic landscapes" (Van Ingen 2004). Although communal practice with other trans and gnc people and trans-centered movement spaces can be particularly meaningful and empowering, "personallypublic" spaces can also foster a bodily freedom and aid in navigating experiences of hyper/invisibility.

\section{Gendered spaces}

For the people I interviewed, access to a movement space was relative to feeling comfortable and being able to move their bodies "freely." This comfort was primarily attributed to how spaces were gendered and how their bodies were gendered in spaces. The normative practices of a space often determined accessibility. For example, one participant claimed "I know initially for me, it was difficult, being trans in a yoga class. It's already being black in a yoga class, as often times the spaces are dominated by thin white women.” The feeling of being minoritized in a space was in regard to the other people participating in the activity, as well as those whom are represented or thought of to be participating. Whether participants shared similar identities or not, there was an emphasis placed on the identities of the leader or teacher.

The same participant went on to describe how in becoming a yoga teacher they were able to transform who had access to yoga and how bodies were gendered in that space; however, this did not come without significant emotional labor. Throughout the teacher training they repeatedly engaged in discussions questioning how bodies were being gendered in yoga spaces. They described being taught in the training “...how bodies, specifically how gendered bodies, are 
supposed to or not supposed to move." For example, when learning the about the squat Malasana, the head instructor claimed that "typically men can't get in this pose." In becoming a yoga teacher, this participant not only changed the dynamic of their yoga classes by not ascribing gender to the way's bodies moved or who was able to access particular positions, but additionally by creating trans and queer-centered classes. This was most impactful for them in transitioning from feeling hypervisible as a trans and queer person in the teacher training and yoga classes, to an intense sense of comfort in seeing the trans and gnc people they taught in trans-centered yoga classes participate in non-trans-centered classes as well. In line with Chernova's study on collective dance, the creation of trans-centered spaces for movement allowed trans yoga students to feel comfortable and empowered in their practice to participate in what may have been previously uncomfortable and constraining spaces, creating "a sense of unity and a shared experience between participants that they could take outside the room now and apply in their lives" (Chernova 2016:431).

Another participant described the discomfort of being the only trans actor cast in a show, claiming: “...if I'm one of the only or the only like non-cis person in a space, it often feels like um, there's like a nervousness to talk about [gender]...I feel like a lot of directors just don't really know how to talk about genderqueer-ness on stage." Directors often assumed this participant would play a specific gender because of how a director believed they were "perceived." Other times, directors would ask what gender they wanted to act. While the capacity to choose a gender felt particularly "powerful" in many instances, regarding acting, they ultimately claimed: "the community spaces that then felt most comfortable, I didn't have to choose." Creating spaces where gender is not a determinant of one's participation in an activity, where it is not constraining, can allow for increased capacity to experience a bodily freedom. 
While many participants described not feeling welcome in dance or formal competitive/organized sport spaces, due to the ways their bodies were incorrectly gendered as well as how other's bodies were hyper-regulated by gendered norms, this was not always the case. In spite of highly gendered and therefore often uncomfortable experiences in volleyball and diving, the community of people on a team was more influential than the norms and confines of a strictly gendered sport. In spite of gendered divisions in formal competitive sporting teams, as long as the team was affirming of a person's gender — whether it aligned with the formal gendered designation of a sport or not — engaging in this community space still provided experiences of bodily freedom through movement practice. More so, one participant discussed moshing, described as a rather "aggressive movement," as particularly affirming to their gender. Through participation in what they described as a "masculine" activity, moshing created a gendered space to explore more stereotypically masculine expressions. While this participant's gender was not overtly discussed or described by the people in the space, the felt sense of participating in a "masculine" movement activity was exhilarating. These experiences reflect the ways gendering and mis-gendering of people can take away the capacity to participate in movement activities that otherwise felt empowering and enjoyable for their bodymind. However, when people engage in gendered movement spaces on their own terms, they still have the capacity to be influential in fostering a felt sense and embodied freedom.

\section{"Personally-Public" Spaces}

In addition to having one's body gendered in movement spaces, having intentional spaces for people to "be with their bodies" was a recurring theme in my conversations with participants. This sentiment was reflected in discussing the importance of movement in their lives. Most 
often, people were prompted by way of a teacher or instructor to be with their body during particular movements. Part of being with one's body was related to the construction of a space. For many, particular movement-based activities, such as dance and weight lifting, were claimed to relieve significant experiences of dysphoria. For some this appeared to be about the ways their bodies could be changed physically by the movement (e.g. increased musculature), but for others it was more about being provided a space to move freely. While in many ways these experiences of reduced dysphoria were dependent on the particular movement, there was also the construction of spaces as simultaneously communal and individual.

Most movement-based activities were described as simultaneously public and private. In reflecting on the dynamics in a yoga class, one person claimed:

...what felt really important for me was that I could be with others but the focus was on my mat. So, I could be, sharing in a practice, I could have access to my body, I could have access to humanity, with a whole bunch of other people doing exactly the same thing, and we did not have to talk to each other. We didn't have to talk... if I veered off of my mat I needed to come back to my mat, so it was such a public, a personally-public practice.

This “personally-public" practice, although not described with identical language, was significant to many in reflecting on enjoyable experiences and aspects of dance classes, running, moshing, diving, walking, and rock climbing.

In yoga and dance classes specifically, a common trend emerges for trans people; the experience of a space as being private enough to wear what feels most comfortable for you, but public enough to not feel alone. This concept, coupled with the idea of intentional spaces that allow oneself to "be" and engage with their body, create simultaneously terrifying and transformative spaces. Movement and moving through space were repeatedly described as defiant acts. In reflecting on the challenges of feeling constrained in her body in the place she was previously living compared to now, one participant claimed: "Now it's really waking up, so 
I've been allowed to start to dance anywhere, be myself because I feel safe, I feel comfortable, and it's a work in progress but I'm getting stronger." The ability to take up space and move comfortably was described repeatedly as a particular "freedom." More so, in reflection of feeling the "personally-public" space of a yoga class one participant discussed the thought process behind wearing a binder to class. They described: "I remember like navigating um, do I wear a binder to class, when I do this I can't breathe as well. When I do this I don't have access, like it literally limits my movements." The ability to feel comfortable in their body without wearing their binder in a yoga class was scary and empowering. Navigating socio-spatial constructions through movement exemplify the ways trans and gnc people have bodily agency, by creating therapeutic landscapes both within and beyond trans-centered spaces.

\section{CONCLUSION}

The body is integral to understanding the impacts of social control and constraint, as well as those of bodily agency and bodily. Trans and gnc bodies are perpetually constrained through social structures informed by hegemonic discourse on gender. Both overt and covert experiences of violence and oppression can manifest in insidious trauma. Research on trans and gnc people's participation in movement-based activities on their own terms elicits numerous prospects for healing through the body and in community. This research locates participation in movementbased activities for trans and gnc people beyond narratives of constraint through a sociophenomenological approach. These findings extend from previous research which has illustrated movement-based activities as more than just constraining and exclusionary. Specifically, this work affirms existing findings on the impacts of collective trans-centered movement practice, and expands such ideas to be applicable to additional activities beyond collective dance practice 
and in "personally-public" movement spaces. In spite of relentless experiences with insidious traumas and subsequent embodied oppression, trans and gnc bodies continue to take up space and assert our existence.

Movement, can be a mechanism by which trans and gnc people use to engage in a practice of bodily awareness, autonomy, and healing in particular spaces. Moving beyond constraint and regulation, bodily agency requires a degree of awareness (consciousness) that can emerge by connecting with a "felt sense" of the body through movement. Contextualizing these in spatial constructions, movement-based activities allow trans and gnc people access to highly gendered spaces on their own terms, beyond the confines of the hyper-/invisibility paradigm. While accessing such a freedom is possible in trans-centered formal and informal therapeutic landscapes, these experiences can also occur in "personally-public" spaces in group-based movement settings. Communal movement practice, regardless of the type of activity, allow participants to operate on their own terms at the interstices of hyper- and invisibility. "Personally-public" movement experiences can further foster a sense of community while removing the focus of hypervisibility for trans and gnc people. These spaces allow trans and gnc people to participate in a practice of bodily freedom through intentional awareness practice on their own terms, that is both healing and an act of resistance.

Although this work expands from previous literature on trans and gnc people's participation in movement-based activities, the current research is quite limited. Further exploration and comparison of the differences between numerous movement-based activities may provide more generalizable results and recommendations for theories on movement as a healing practice for trans and gnc people, as well as the socio-spatial constructions of specific movement spaces. Additional research on breathwork could illuminate more information on the 
ways breath and taking up space are connected. Despite a range of identities amongst a small sample size, the total number of participants in this study remain relatively small. A more thorough examination of the differing experiences of trans people within and beyond the gender binary may illuminate further implications for the ways gender is constructed through movement and space. While previous research emphasizes the ways engagement with movement-based activities change over time for trans people pursuing medical transitions, research on the experiences of trans and gnc people not pursuing medical transitions' engagement in movement over time is necessary.

More specifically, the role of time with regard to actions and bodily agency deserves further exploration in 3 possible ways: action as part of a trajectory over time, action as episodic throughout time, and action as ritualistic with regard to particular time. Conceptualizing action as a process of becoming over time with regard to gender and movement-based activities, may expand theoretical understandings of agency through action. This perspective would further allow increased emphasis on the interplay between time and space. More so, the accompaniment of ethnographic participant observation as an additional research methodology, could highlight the socio-phenomenological relationship between space and time in movement-based activities for trans and gnc people.

Although movement was more often than not a mechanism for fostering a positive relationship with one's body, the focus of the research may have negated discussions of the negative implications of movement practices. This may have altered results to be overwhelmingly optimistic. However, rather than considering this work on a positive/negative binary, I consider the focus on movement as healing to be reflective of the generative knowledge that can emerge amongst people with marginalized identities (Kafai 2013). Or rather, as a 
proclamation, which emphasizes the characteristics of movement and spatial construction as more impactful than the specific movement-based activity.

Exploring the experiences of movement-based activities for trans and gnc people lend both theoretical and empirical implications on the constructions of space, gender, and performativity. These findings show that movement-based activities support trans and gnc people in healing from the impacts of insidious traumas through dynamics of navigating agency and constraint. In reflection of the perpetual violence impacting trans and gnc people, which disproportionately impacts trans women and trans femme people of color, further emphasis in research on the processes of healing from embodied oppression outside of formal therapeutic landscapes is critical. 


\section{References}

Adelman, Miriam and Lennita Ruggia. 2016. "Sociology of the Body." Current Sociology Review. 64(6) 907-930. doi: 10.1177/0011392115596561

Ahmed, Sara. 2006. Queer Phenomenology: Orientations, Objects, Others. Durham: Duke University Press.

Allen-Collinson, Jaquelyn. 2009. "Sporting Embodiment: Sports Studies and the (continuing) Promise of Phenomenology." Qualitative Research in Sport and Exercise.1 (3): 279-296

Butler, Judith. 1990. Gender trouble: Feminism and the subversion of identity. New York: Routledge.

Bailey, Marlon M. 2014. "Engendering space: Ballroom culture and the spatial practice of possibility in Detroit. Gender, Place \& Culture." 21(4): 489-507. doi: 10.1080/0966369X.2013.786688

Chernova, Dasha. 2016. "The Right to Dance as the Right to the Body." The Journal of Social Policy Studies. 14(3):423-436.

Doan, Petra L. 2010. "The tyranny of gendered spaces - reflections from beyond the gender dichotomy." Gender, Place \& Culture 17(5): 635-654 doi: 10.1080/0966369X.2010.503121

Elling-Machartzki, Agnes. 2017. "Extraordinary body-self narratives: sport and physical activity in the lives of transgender people." Leisure Studies. 36(2): 256-268 doi: 10.1080/02614367.2015.1128474

Giddens, Anthony. 1991. Modernity and Self-Identity: Self and Society in the Late Modern Age. Cambridge: Polity Press. 
Giddens, Anthony. 1984. The Constitution of Society: Outline of the Theory of Structuration. Berkeley: University of California Press.

Gieseking, Jen Jack. 2013. A Queer Geographer's Life as an Introduction to Queer Theory, Space, and Time Introduction In Queer Geographies: Beirut, Tijuana, Copenhagen. 2014 Roskilde: Museet for Samtidskunst. Lau, Lasse, ed. Grosz, Elizabeth A. 1994. "Volatile Bodies: Toward a Corporeal Feminism” In Refiguring Bodies. 3-24. Publisher: Bloomington: Indiana University Press.

Hanan, M. E.. 2012. "Embodied Therapy for Clients Expressing Gender Variation: Using Creative Movement to Explore and Express Body Image Concerns." Expressive Therapies for Sexual Issues, 1-38. doi:10.1007/978-1-4614-3981-3_1

Heyes, Cressida J. 2018. "Two Kinds of Awareness: Foucault, the Will, and Freedom in Somatic Practice." Human Studies.

Van Ingen, Cathy. 2004. "Therapeutic Landscapes and the Regulated Body in the Toronto Front Runners." Sociology of Sport Journal. 21(3): 253-269. doi:10.1123/ssj.21.3.253.

Kafai, Shayda. 2013. “The Mad Border Body: A Political In-betweeness.” Disability Studies Quarterly. 33(1).

Karcher, O. P., \& Caldwell, C. 2014. "Turning data into dance: Performing and presenting research on oppression and the body." The Arts in Psychotherapy. 41(5): 478483. doi: 10.1016/j.aip.2014.09.001

Kinkaid, Eden. 2018. “(en)Vision(ing) Otherwise: Queering Visuality and Space in Lefebvre's Production." GeoHumanities. 
doi: 10.1080/2373566X.2018.1447496

Leedy, Gail. 2009. "I Can't Cry and Run at the Same Time.” Affilia. 24(1);80-93. doi:10.1177/0886109908326999.

Massey, Doreen B. 1994. Space, Place, and Gender. Minneapolis: University of Minnesota Press.

Mizock, Lauren and Thomas K. Lewis. 2008. "Trauma in Transgender Populations: Risk, Resilience, and Clinical Care Lauren.” Journal of Emotional Abuse, 8(3) doi: $10.1080 / 10926790802262523$

Porter, James N., Luther H. Martin, Huck Gutman, and Patrick H. Hutton. 1989. "Technologies of the Self: A Seminar with Michel Foucault." Contemporary Sociology 18(1):153-53.

Root, Maria P. P. 1992. "Reconstructing the impact of trauma on personality." In Personality and Psychopathology: Feminist Reappraisals, ed. L. S. Brown \& M. Ballou. New York: Guilford.

Rubin, Henry S. 1998. “Phenomenology as Method in Trans Studies.' GLQ. 4(2): 26381.

Salamon, Gayle. 2010. Assuming a Body: Transgender and Rhetorics of Materiality. New York: Columbia University Press. Retrieved April 13, 2018.

Salamon, Gayle. 2014. "Phenomenology." TSQ 1(1-2): 153-155. doi: https://doi.org/10.1215/23289252-2399884

Shelley, Christopher A. 2008. Transpeople: Repudiation, Trauma, Healing. University of Toronto Press.

West, Candace, and Don H. Zimmerman. 1987. "Doing Gender." Gender and Society. 
1(2): 125-151. JSTOR, www.jstor.org/stable/189945. 